\title{
CARING MORE BY DOING LESS? AN ENQUIRY ABOUT THE IMPACTS OF OUTSOURCING ON PATIENT CARE
}

\author{
${ }^{1}$ Federica Brunetta, ${ }^{1}$ Luca Giustiniano and ${ }^{2}$ Lucia Marchegiani \\ ${ }^{1}$ Department of Business and Management, LUISS Guido Carli University, Italy \\ ${ }^{2}$ Department of Business Studies, RomaTre University, Italy
}

Received 2013-11-06; Revised 2013-12-21; Accepted 2013-12-24

\begin{abstract}
This study seeks to understand the potential impact of outsourcing on healthcare processes. By referring to a wider scope of industries and sectors, as they have been the experimental fields of most of the studies on outsourcing, we highlight the pros and cons of the externalization of activities related to patient care. Our purpose is to show and contextualize the (yet) ambiguous effects of relying on external partners in delivering services related to the health of patients. We argue that the seek for efficiency might sometimes hinder the global outcome of care; further we state that given the peculiar nature of the healthcare, outsourcing needs to be used within a wider strategic analysis of the activities. This study starts with a review of the literature on outsourcing strategies applied to healthcare sector and it also proposes an analytical model for decision-making. The main conclusion is that healthcare organizations should set up proper mechanisms for the governance of the overall transactions related to outsourcing in order to extend the span of control over the external providers as long as the effectiveness and the efficacy of the general outcome is not compromised. Both private and public health providers could benefit from a more reliable model for deciding on the span of their activities that can be outsourced.
\end{abstract}

Keywords: Outsourcing, Externalization, New Public Management, Efficiency, Patient Care

\section{INTRODUCTION}

Outsourcing as a strategic choice for organizations has experienced a widespread in the 1980s-90s of the last century. Although the practice of outsourcing is generally related to some genetic fields (manufacturing and other serial services), more recently a new strong wave of outsourcing has gained momentum not only in healthcare but also in other person-related services (Pholpanga et al., 2011; Chantachan, 2011; Kavya and Bai, 2014; Baroudy and Lala, 2014). Further, the advance of Information and Communication Technology (ICT) is enabling various forms of remote coordination of activities (e.g., remote diagnosis, clinical reporting) enhancing the possibility to purchase them from external providers (Amindoust et al., 2012). Differently from many other sectors, the impact of such choices on the general outcome of healthcare organizations is particularly difficult to be assessed. Some aspects like data security; organizational climate and development of internal competencies; accountability and accuracy of purchased services have a higher magnitude when they refer to hospitals, health departments, ambulatories.

Within this general framework, the present global scenario is heterogeneous and fragmented given the diversity of health systems across countries. Historically, health systems based on private insurance (e.g., USA) have been the first ones to implement outsourcing practices, given the similarity of their competitive pressures with some other competitive arenas. Where the public health systems have embedded some competitive mechanisms, either by establishing forms of provider/purchaser relationships between public entities and private providers, or else by being partially privatized (e.g., NHS, Italian SSN, Swedish Health Systems), the traditional "adversarial" vision between

Corresponding Author: Federica Brunetta, Department of Business and Management, LUISS Guido Carli University, Italy Tel: + 390685225438 
the public authorities and private business has been abandoned and outsourcing has flourished in such context where the initial pressure on efficiency has generally implied a massive externalization of activities. Such trend has also somehow benefitted from the advent of the New Public Management, which has imported mechanisms and logics typical of private companies into public sectors, including healthcare in many cases (Avery, 2000; Segouin et al., 2005; Marchegiani et al., 2012; Giustiniano et al., 2014). Nevertheless, the topic seems to be very important whereas some health systems are in the process of expanding their public presence (e.g., USA).

This article aims at entangling the dynamics of the net benefits stemming from outsourcing, as a specific context of supply chain optimization (Nenni and Giustiniano, 2013), by starting from its general aspects and converging towards its specificity in healthcare. It covers two main problems: (a) the scope of outsourcing. Although it could involve both core and support activities, the adoption of models and practice developed in other industries could be misleading in healthcare in terms of performance, or more dangerously detrimental for the health outcomes, given the high level of their interrelation; (b) impact assessment. Since the measure of the global outcome of healthcare requires considering both efficiency gain (due to clinical and technical aspects) and patient care (which embeds emotional aspects), a conclusion may be traced that suggests the existence of a theoretical peak of net benefits of outsourcing.

\subsection{Conceptual Framework: The Outsourcing Strategy and its Implications in Healthcare}

Although a unique definition of outsourcing is not available, in general we refer to this as a strategic decision to outsource a process, which was initially handled internally. Generally, the motivation behind the choice of outsourcing lies on economic basis, which lead to decide to outsource some activities in which the organization holds no special skills or fail to exploit economies. In hospitals it is the common case for support activities like catering, cleaning, management of information systems. As mentioned before the use of outsourcing strategy in public organizations responds to the transformation of the logics behind the delivery of public services, which have been progressively aligned to those of the private sectors. To this extent, the importance of outsourcing in the National Health Service (NHS) should be included in the broader issue related to the opportunity to instill a managerial logic in the field of public services. This takes place in the framework given by the intersection between the so-called New Public Management (Alonso et al., 2013; McLaughlin et al., 2002) and the approach to Public Governance. Generally speaking, the outsourcing strategy resembles a typical make-or-buy dilemma, which compares the opportunity of implementing some activities within the boundaries of an enterprise, with the alternatives of having external suppliers carrying out those activities due to either cost savings or quality enhancement opportunities. Indeed, the choice of outsourcing allows organizations to dismiss some functions in favor of focusing on the activities in which it holds the key resources and skills. This is the main reason, coupled with that of cost reduction, which drives more and more companies to outsource.

Moreover, the outsourcing vendors typically play the role of external partners, since a decision to outsource some activities implies a rather extended duration of the supply and thus involves also creating and maintaining a relationship based on trust with partners.

Given this overall picture, it is clear that the issue of outsourcing should be investigated from various perspectives. In fact, it is possible to highlight aspects of: (i) strategic management outsourcing (Prahalad and Hamel, 1990; Sanchez, 1995); (ii) organizational approach (Carlsson, 1989); (iii) legal-institutional (Domberger, 1999; Hart, 1995); (iv) management of human resources (Leimbach, 2005; Marsden, 2004); (v) globalization (Grossman and Helpman, 2005; Yu, 2012); (vi) management of operations (Morroni, 2009; Chang and Lo, 2011); (vii) innovation (Long, 2005). Therefore, managing the outsourcing strategy means structuring the entire organization in order to respond adequately to the different problems that this strategic choice implies.

Many papers have highlighted the most controversial aspects of the practice of outsourcing. In particular, several studies show that in a large majority of cases, outsourcing projects do not meet predetermined financial goals (Malone, 2004). For this reason it is necessary to create a governance system for outsourcing, which, in the first instance, should be able to control the determinants of risk that occur in the case of outsourcing of processes and services.

In general, the potential benefits of outsourcing are the following: the ability to focus on its core activities by delegating to other routine management operations and limited strategic value; the reduction of operating costs; the acceleration of change processes; the raising of skills and functions not available within the company; the possibility of acquiring more power to control activities or functions are difficult to manage. 
It is also true that many contributions have shown that there are several weaknesses of the outsourcing strategy (McIvor, 2008), such as: fear of losing control of some companies of the functions given in trust to a third party; reluctance to share data with third parties confidential or strategic importance; difficulty of re-use of human resources that can be made redundant after the transfer of some functions to outsourcing companies.

The above-mentioned factors threaten the success of outsourcing practices in the private sectors as well as in the public one. In fact, it is well recognized that outsourcing and decentralization does not automatically and necessarily lead to a more competitive organization, as the success of outsourcing passes through a cultural change, organizational structure and ability to adapt and an extremely complex coordination.

\section{MATERIALS AND METHODS}

This study is a short review article summarizing multiple studies on the outsourcing strategies applied to healthcare sector. We collected the extant literature on the topic using the databases PubMed, Elsevier Science, ISI Web of Knowledge, EBSCO and Google Scholar. The key search terms were: Outsourcing, externalization, New Public Management and outsourced processes. Secondary search terms were: Offshoring, efficiency, patient care. The search was conducted between January 2010 and November 2011 and was limited to studies in English and Italian. The body of knowledge that we collected comprises publications from diverse fields, ranging from economics to management and medicine, published between 1989 and 2011.

\subsection{Analytical Framework: Outsourcing in Healthcare Services}

Healthcare organizations, including hospitals, nursing homes, long-term care facilities, professional services groups and specialized facilities are increasingly considering and deploying outsourcing decisions. Undoubtedly, the initial focus of outsourcing in healthcare has been on the non-clinical services, outside the main value stream, with a strong emphasis on peripheral services (Brunetta and Marchegiani, 2009). In this light, the externalization of non-clinical services has gained increasing importance for all noncore functions, while the externalization of clinical services remains related to those core activities where it is fundamental to reduce costs and acquire specialized knowledge by external partner.
Several authors (Roberts, 2001; Burmahl, 2001; Lorence and Spink, 2004; Foxx et al., 2009) have analyzed the type of activities that are being outsourced by healthcare organizations. The development and operation of information systems are regarded as those services that are most likely to be outsourced (Lorence and Spink, 2004; Giustiniano et al., 2014) but authors have also analyzed the outsourcing of other activities such inventory management (Nicholson et al., 2004) and ancillary services security, laundry, food, hazardous waste, cleaning, parking, reservations and call-centers (Burmahl, 2001; Lepeak and Voytek, 2008). Despite the wide amount of activities being outsourced, healthcare still has to reach the scale or scope seen in other industries with outsourcing areas in which healthcare organizations seem to be reticent to move ahead as quickly.

More generally, authors (Roberts, 2001; Macinati, 2008) recognize that ancillary services are more likely to be outsourced, as they are considered strategically less important by healthcare organizations. Diagnostics and clinical services tend to be managed internally, due to their importance, although laboratory services and nursing are increasingly being outsourced. Some argue that most healthcare organization will opt for a portfolio approach (Gupta et al., 2008) that will include the externalization of different types of healthcare activities, dividing them into activities that must be performed by specialized resources on site (usually core-activities), activities that can be performed by non-specialized resources on site, task that can be performed by humans off-site and task that can be carried out by machines without human involvement.

Outsourcing choices are driven by the necessity to reduce costs and increase efficiency, as a result of the increased attention to the rise of healthcare expenditure and the decrease of quality in services and by strategic considerations, as a result of managerial choices to focus on core activities to increase competitive advantage while externalizing the peripheral and non-core activities (Roberts, 2001; Macinati, 2008; Billi et al., 2004). Outsourcing provides the benefit of flexibility, enhancing the capability of the organization to face changing environments, as adaptation does not require reconfiguring internal resources (Roberts, 2001).

Moreover, in healthcare the focus of institutional and societal organizations is very strong due to the attention to legal and social aspects, related to quality and expenditure levels. In this light, the institutions, defined as all the collective and regulatory complexes consisting 
of political and social agencies that regulate organizations' actions via the enforcement of the laws, rules and norms (DiMaggio and Powell, 1983), constrain the outsourcing choices of healthcare actors, especially for what concerns budgeting, human resources management and quality assistance standards.

The dominant literature agrees on the cost containment aspect, relating it to potential benefits of decreasing expenditure while increasing efficiency (Roberts, 2001; Billi et al., 2004). Nonetheless, cost reduction is not always in line with the expectation of managers: outsourcing is likely to have scarce positive effects on financial performance (Macinati, 2008) and cost-effectiveness of outsourcing choices is becoming a main concern (Burmahl, 2001). Pressures from institutions to reduce healthcare expenditure have driven managers to externalize services and activities traditionally managed in-house, leveraging scale economies and focusing on the expertise of the outsourcee.

Efficiency is now shifted to the relationship with partners who can exploit distinctive competences in the functions to be externalized and through the flexibility and innovative capabilities that can be reached exploiting technologies and knowledge of the outsourcer and the outsourcee (Roberts, 2001; Amindoust et al., 2012). A number of specialized companies and vendors are emerging in response of extensive outsourcing choices, with growing quality service, it has been argued that the less the healthcare organization use outsourcing, the slower it will be the development of high standards among outsourcees (Lorence and Spink, 2004).

On the strategic side, outsourcing can be seen as an instrument that managers can use to maintain a focus on the core competences (Roberts, 2001; Billi et al., 2004). Nonetheless, there is a high risk of fragmentation of control on the core activities and on externalized functions (Roberts, 2001; Billi et al., 2004). In fact, it is not always clear which core and non-core activities shall be externalized (Billi et al., 2004; Macinati, 2008) and this issue can lead to a mistakes in externalizing competences that are critical for the success and competitive advantage of the organization (Roberts, 2001), exposing the organization to the risk of services below the standards.

Outsourcing can be used as a response to institutional pressure, solving problems of turnover, incomes, selection and training. Even in those activities that looking at quality/performance ratios would not be externalized otherwise (Macinati, 2008), outsourcing specialized services can be a strategic option when keeping them in-house would require special training or new hiring (Burmahl, 2001).

\section{ANALYTICAL MODEL}

The illustration of the potential impact of outsourcing on healthcare practice could be analyzed from several different standpoints. Nevertheless we consider an analysis of the impact of outsourcing on the general outcome of health care could be up to the task.

To begin with we could adopt a general definition of the net global outcome of Outsourcing (O) as the linear combination of the perceptive elements considered by the Patient (P) and the technical outputs, measured as the Efficiency and Efficacy Gain (EEG) delivered by the healthcare organization, minus the Relational Quality and the Costs of Coordination (CC):

$$
\begin{gathered}
\mathrm{O}=\mathrm{SP}+\mathrm{EEG}-\mathrm{RQ}-\mathrm{CC} \\
\mathrm{SP}=\sum_{\mathrm{i}} \mathrm{SP}_{\mathrm{i}} \\
\mathrm{RQ}=\sum_{\mathrm{i}} \mathrm{RQ}_{\mathrm{i}} \\
\mathrm{EEG}=\sum_{\mathrm{E} E \mathrm{E} i} \\
\mathrm{CC}=\mathrm{C}(\mathrm{i})+\mathrm{IC}
\end{gathered}
$$

In terms of Perception $(\mathrm{P})$, the presence of several providers transforms the comprehensive output into a sum of sub-outputs $\left(\mathrm{P}_{\mathrm{i}}\right)$ delivered by heterogeneous partners (Ibrahim and Ibrahim, 2013; Nibardo et al., 2013). The perceived quality of such a suite of different sub-elements could have a positive impact on the final receiver (patient) given to the highest degree of perceived Specialization $\left(\mathrm{SP}_{\mathrm{i}}\right)$ of the providers (e.g., catering, cleaning) (Fig. 1). This overall benefit could be sustained as long as the outsourcer (healthcare organization) is able to govern all the relations with the providers and be the final interface (front-end) with the patient; on the contrary, if the patient is exposed to different companies the plurality of interfaces could compromise the perceived level of relational quality might be different $\left(R Q_{i}\right)$ (Fig. 1). From this perspective then a maximum theoretical range of outsourceable activities could be justified; it is also intuitive to state that the mentioned risk is higher when it comes to activities related to the core activities (nursing, secondary care). 


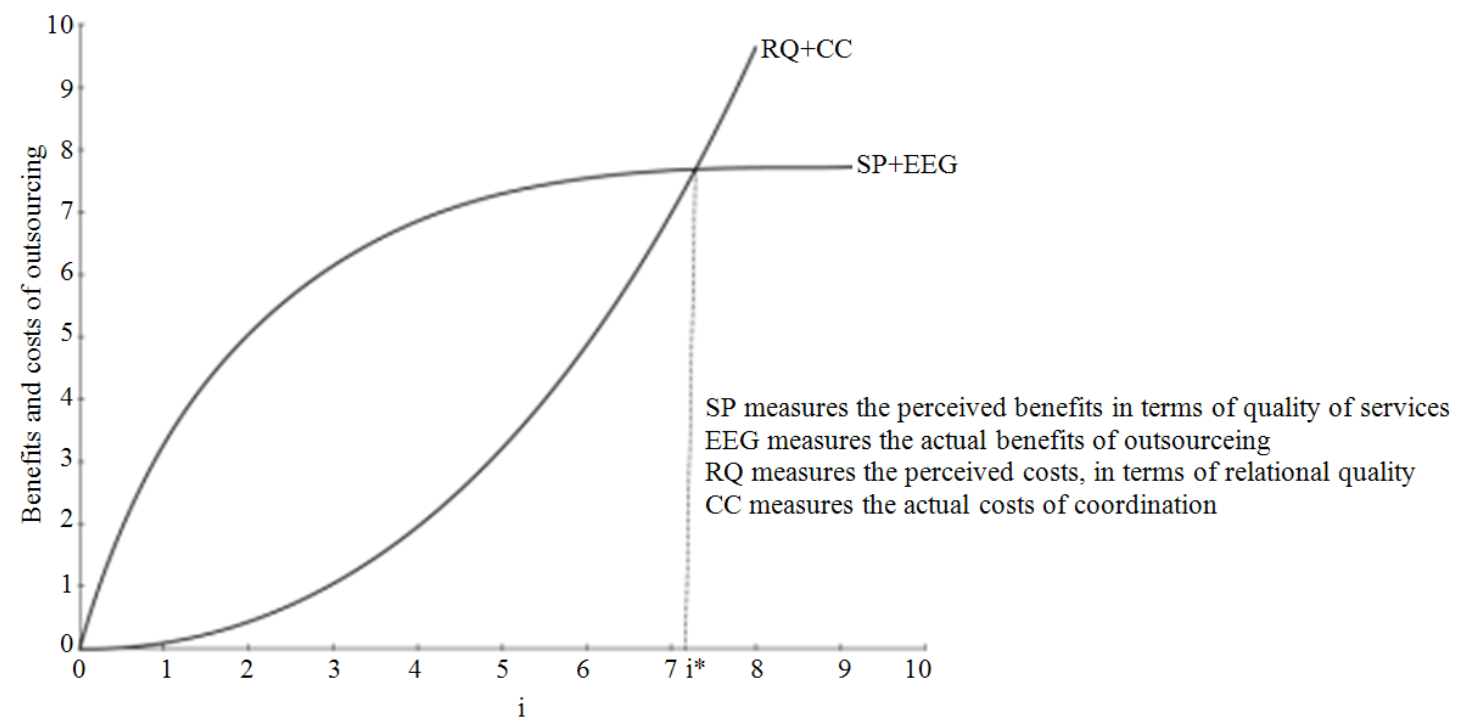

Fig. 1. Net advantage of outsourcing, as a combination of the total costs of outsourcing (RQ+CC) and the total benefits of outsourcing $(\mathrm{SP}+\mathrm{EEG})$

The technical aspects related to the clinical outputs (diagnosis, treatments) could also benefit from outsourcing when specialized providers are involved (Efficiency and Efficacy Gain-EEG). The span of their involvement could include both support (e.g., cleaning) and core activities (e.g., laboratory analysis, laboratory or RX reports) (Fig. 1). Similarly to the perceptive component of the global outcome, the benefit the health organizations could exploit seem to be limited to the governance capability of the focal organization. The costs of general Coordination (CC) of all the activities (sub-outputs) are related to the costs that the outsourcing health care organization bear with the aim of coordinating the activities of the outsourcees, which grow at an exponential pace $\left(\mathrm{e}^{\mathrm{i}}\right)$ and the costs associated to obtaining homogeneous interfaces between the outsourcees and the patients (IC). When i increases, CC could overtake the single benefit in terms of efficiency and/or effectiveness by impacting on a negative way on the accountability of decision processes or technical quality of the outcome (e.g., problems related to diverse standards, interfaces, protocols) (Fig. 1).

Given that SP measures the perceived benefits in terms of quality of services, it is a function if $i$ with $d \mathrm{SP}^{\mathrm{I}}>0$ and $\mathrm{dSP}^{\mathrm{II}}<0$, for the decreasing marginal returns of increasing number of $i$.

EEG measures the actual benefits of outsourcing. Again, it is a function of $i$, with dEEGI $>0$ and dEEGII $<0$.

RQ measures the perceived costs, in terms of relational quality, with $\mathrm{RQI}>0$ and $\mathrm{dRQII}>0$, for the increasing marginal costs of relational quality.
$\mathrm{CC}$ measures the actual costs of coordination, with $\mathrm{dCCI}>0$ and $\mathrm{dCCII}>0$.

The combination of the two elements leads to the conclusion that considering both the perceptive and the technical side of the health outcome a maximum extension of the outsourcing must exist (i $\left.{ }^{*}\right)$ (Fig. 1).

That implies that healthcare organizations should set up proper mechanisms for the governance of the overall transactions related to outsourcing in order to extend the span of control over the external providers as long as the effectiveness and the efficacy of the general outcome is not compromised. As suggested in the most advanced studies on the topic, by recurring to outsourcing programs rather than spot transactions could enhance the governance capability of the focal organization over time (Marchegiani et al., 2012).

\section{CONCLUSION}

The illustration of the potential impact of outsourcing on healthcare practice may be analyzed from several different standpoints. Our model considers both the perceptive and the technical side of the health outcome. We argue that healthcare organizations should set up proper mechanisms for the governance of the overall transactions related to outsourcing in order to extend the span of control over the external providers as long as the effectiveness and the efficacy of the general outcome is not compromised. As a direct implication, both private and public health providers could benefit from a more reliable model for deciding on the span of their activities. 


\section{REFERENCES}

Alonso, J. M., J. Clifton and D. Diaz-Fuentes, 2013. Did new public management matter? An empirical analysis of the outsourcing and decentralization effects on public sector size. Pub. Manag. Rev. DOI: 10.1080/14719037.2013.822532

Amindoust, A., S. Ahmed and A. Saghafinia, 2012. Supplier selection and performance evaluation of telecommunication company. Am. J. Eng. Applied Sci., 5: 49-52. DOI: 10.3844/ajeassp.2012.49.52

Avery, G., 2000. Outsourcing public health laboratory services: A blueprint for determining whether to privatize and how. Public Admin. Rev., 60: 330337. DOI: 10.1111/0033-3352.00095

Baroudy, R. and B. Lala, 2014. Computer-aided decision system for refractive surgeries with excimer laser. J. Comput. Sci., 10: 233-239. DOI: 10.3844/jcssp.2014.233.239

Billi, J.E., C.W. Pai and D.A. Spahlinger, 2004. Strategic outsourcing of clinical services: A model for volume-stressed academic medical centers. Health Care Manage. Rev., 4: 291-297.

Brunetta, F. and L. Marchegiani, 2009. L'outsourcing nella sanità. Consumatori, Diritti e Mercato, 10: 57-68.

Burmahl, B., 2001. The pros and cons of outsourcing. Health Facilit. Manage., 14: 16-16.

Carlsson, B., 1989. The evolution of manufacturing technology and its impact on industrial structure: An international study. Small Bus. Econ., 1: 21-37. DOI: 10.1007/BF00389914

Chang, Y.T. and C.Y. Lo, 2011. Research on the decision model for self-production and outsourcing choices under limited production capacity. J. Math. Stat., 7: 157-164. DOI: 10.3844/jmssp.2011.157.164

Chantachan, S., 2011. A Comparative study of the development model in education and religion management process between Thailand and Lao. J. Soc. Sci., 7: 209-212. DOI: 10.3844/jssp.2011.209.212

DiMaggio, P.J. and W.W. Powell, 1983. The iron cage revisited: Institutional isomorphism and collective rationality in organizational fields. Am. Sociol. Rev., 48: 147-160.

Domberger, S., 1999. The Contracting Organization: A Strategic Guide to Outsourcing. 1st Edn., Oxford University Press, Oxford, ISBN-10: 0198774575, pp: 248.
Foxx, W., M. Bunn and V. McCay, 2009. Outsourcing services in the healthcare sector. J. Med. Market., 9: 41-55. DOI: 10.1057/jmm.2008.30

Giustiniano, L., L. Marchegiani, E. Peruffo and L. Pirolo, 2014. Understanding Outsourcing of Information Systems. In: Approaches and Processes for Managing the Economics of Information Systems, Tsiakis, T., T. Kargidis and P. Katsaros (Eds.), pp: 199-220.

Grossman, G.M. and E. Helpman, 2005. Outsourcing in a global economy. Rev. Econ. Stud., 72: 135-159. DOI: 10.1111/0034-6527.00327

Gupta, A., R.K. Goyal, K.A. Joiner and S. Saini, 2008. Outsourcing in the healthcare industry: Information technology, intellectual property and allied aspects. Inform. Res. Manage. J., 21: 1-26. DOI: 10.4018/irmj.2008010101

Hart, O., 1995. Corporate Governance: Some theory and implications. Econ. J., 105: 678-689.

Ibrahim, O.H.M. and R.M. Ibrahim, 2013. Community pharmacists' involvement in breast cancer health promotion in United Arab Emirates (UAE). Am. J. Pharmacol. Toxicol., 8: 155-163. DOI: 10.3844/ajptsp.2013.155.163

Kavya, G. and V.T. Bai, 2014. Design and implementation of global positioning system receiver in field programmable gate array with short message service. J. Comput. Sci., 10: 91-98. DOI: 10.3844/jcssp.2014.91.98

Leimbach, M.P., 2005. Invited reaction: Outsourcing relationships between firms and their training providers: The role of trust. Hum. Resource Dev. Q., 16: 27-32. DOI: $10.1002 / \mathrm{hrdq} .1122$

Lepeak, S. and M. Voytek, 2008. Emerging outsourcing trends in the healthcare industry.

Long, N.V., 2005. Outsourcing and technology spillovers. Int. Rev. Econ. Finance, 14: 297-304. DOI: $10.1016 /$ j.iref.2004.12.004

Lorence, D.P. and A. Spink, 2004. Healthcare information systems outsourcing. Int. J. Inform. Manage., 24: 131-145. DOI: 10.1016/j.ijinfomgt.2003.12.011

Macinati, M., 2008. Outsourcing in the Italian national health service: Findings from a national survey. Int. J. Health Plann. Manage., 23: 21-36. DOI: $10.1002 / \mathrm{hpm} .902$

Malone, T.W., 2004. The Future of Work: How the New Order of Business Will Shape Your Organization, Your Management Style, and Your Life. 1st Edn., Harvard Business School Press, Boston, Mass., ISBN-10: 1591391253, pp: 225. 
Marchegiani, L., L. Giustiniano, E. Peruffo and L. Pirolo, 2012. Revitalising the outsourcing discourse within the boundaries of firms debate. Bus. Syst. Rev., 1: 157-177. DOI: 10.7350/BSR.A13.2012

Marsden, D., 2004. The role of performance-related pay in renegotiating the "Effort Bargain": The case of the British public service. Indus. Labor Relat. Rev., 57: 350-370.

McIvor, R., 2008. What is the right outsourcing strategy for your process? Eur. Manage. J., 26: 24-34. DOI:10.1016/j.emj.2007.08.008

McLaughlin, K., S.P. Osborne and E. Ferlie, 2002. New Public Management: Current Trends and Future Prospects. 1st Edn., Routledge, New York, ISBN10: 0203996364, pp: 368.

Morroni, M., 2009. Production Process and Technical Change. 1st Edn., Cambridge University Press, Cambridge, ISBN-10: 0521119731, pp: 236.

Nenni, M.E. and L. Giustiniano, 2013. Increasing integration across the supply chain through an approach to match performance and risk. Am. J. Applied Sci., 10: 1009-1017. DOI: 10.3844/ajassp.2013.1009.1017

Nibardo, P.A., J.A. Mata-Marin, J. Gaytan-Martinez, G. Huerta-Garcia and B. Acosta-Cazares, 2013. Clinical and sociodemographic risk factors for tuberculosis in human immunodeficiency virus infected patients. Am. J. Infect. Dis., 9: 142-147. DOI: 10.3844/ajidsp.2013.142.147
Nicholson, L., A.J. Vakharia and S.S. Erenguc, 2004. Outsourcing inventory management decisions in healthcare: Models and application. Eur. J. Operat. Res., 154: 271-290. DOI: 10.1016/S03772217(02)00700-2

Pholpanga, O., S. Phothisane and K. Paengsoi, 2011. Unidentified corpses: Development of management model in charity organizations of Chinese-Thai people. J. Soc. Sci., 7: 605-610. DOI: 10.3844/jssp.2011.605.610

Prahalad, C.K. and G. Hamel, 1990. The Core Competence of the Corporation. Harvard Bus. Rev., 1: 79-91.

Roberts, V., 2001. Managing Strategic outsourcing in the healthcare industry. J. Healthc. Manage., 46: 239-249. PMID: 11482242

Sanchez, R., 1995. Strategic flexibility in product competition. Strategic Manage. J., 16: 135-159. DOI: $10.1002 /$ smj.4250160921

Segouin, C., B. Hodges and P.H. Brechat, 2005. Globalization in health care: Is international standardization of quality a step toward outsourcing. Int. J. Q. Health Care, 7: 277-279. DOI: 10.1093/intqhe/mzi059

Yu, Z., 2012. Economies of scope and patterns of global outsourcing. Rev. Int. Econ., 20: 854-868. DOI: $10.1111 /$ j.1467-9396.2012.01060.x 